\title{
Research on Educational Form Innovation of Universities Values under Big Data Era
}

\author{
Yuntao Liu \\ XiJing University, shaanxi 710123 China \\ 592633690@qq.com
}

Keywords: Dig date; Values; Education mode; Innovation

\begin{abstract}
Now days, with a rapid developing society, developed technology, information communicating, the communication between people is more and closer and the life is becoming more and more convenient. Big date is a production of high technology. Under big date ages, the educational work of universities' values directly affects the future of universities and the individual development of students. How to grasp the opportunities and challenges and innovating the education model of values appropriately, to improve the timeliness of universities "value education is becoming problems needing to consider.

With the coming of cloud era, big date attracting more and more attention, its application more and more reflects its advantages, occupies more and more areas. There are 50 million pictures upload per day and twenty hours video shared per miniature. The value brought by big date is recognized gradually. By innovation and development of technology and data's feeling, collecting, analyzing, sharing, providing people a new way to viewing the world, this way of thinking will promote some societies used to rely on 'almost done 'operations to carry out huge reforms. Although college student's knowledge construction is complete, due to the active thinking ways, students are easy to be affected by the wave of big data, so, universities and colleges should carry out related innovation reforms on values education and grasp the opportunities, go with difficulties to promote the health development of students.
\end{abstract}

\section{The Challenges of Universities Values Education under Big Data}

After the Internet of things, cloud computing, big data begins to debut. In the era of big data, we need more comprehensive data to improve the accuracy of the analysis (prediction), so we need cheap, convenient and automatic data production tools. In addition to our use of the Internet in the virtual world browser, software intentionally or unintentionally left behind a variety of personal information data, we are using mobile phones, smart watches, smart bracelet, smart necklaces and other wearable digital product production data. Our router, TV, air conditioning, refrigerator, water dispenser, vacuum cleaner, smart toys, etc. also began to become more intelligent and has had the networking capabilities, which is at the same time to better serve us, but also in the production of a large number of data. Even we go out shopping, merchants router, operators' WLAN and 3G, ubiquitous electronic camera eye, self-service screen department store, the bank's ATM, gas station and across various convenience store credit card machine all are producing and collecting data.

In our country, college students can be said to be the main audience of the network, as the main group of data use, manufacture and share, are also the main force to promote the development of science and technology. The development of network platform and the wide use of smart phones, QQ, micro-blog, WeChat and other software development and utilization, are convenient to facilitate the acquisition of information, search and dissemination. If colleges and universities can use valuable education information, it can help to reform the traditional education mode, which is beneficial to the innovation of the values of the university education. That is, if the university is able to grasp the data resources of the era of big data, it can become a winner in education.

Seeing from the perspective of the law of physical and mental development of College students, in the adolescent stage of them, the outlook on life and values are not stable, especially in this era of diverse values and complex information, and it is difficult to coordinate the contradiction between 
self-personality and social value. In this case, the richness of the data resources may also become a barrier to the healthy development of College Students. Many college students like to surf the Internet, but learned information did not have a positive influence on College Students' study and life, phubber and Thumb tribe are bound to affect the student's academic achievement and interfere with the normal order of learning. In addition, a variety of information in the network environment is uneven; University Students' values are easily misled by false information and speech, it is worth further discussion that how to take a place in the network education foe universities, correctly to guide of College Students' values through the network platform.

At present, the change of university values education and university students' values is being not harmonious and the pace being backward, cannot meet the needs of College Students' values education. For example, many university teachers only pay attention to the professional teaching content, and ignore the guidance of College Students' values, relatively vague teaching content, mainly teachers to transmit knowledge, single teaching means, result in many large U-shaped and monk learning enthusiasm, attitude of students problems, the values of ineffective education. Colleges and universities need to think about how to seize the opportunity of the era of big data to reform the form of values education, innovating the contents and ideas of education and promote the healthy development of students

\section{Study on the Form Innovation of Value Education in Colleges and Universities}

Values education in Colleges and universities only keep up with the pace of development of the era of big data and deep into real life which can arouse students' learning interest and arouse students' resonance to make students feel the power of value education, and to improve the effect of education. Here are a few good results of the value of education form.

Online Game Based Education. Through the use of network game platform, designing different clearance Games, at the same time, the correct values, inspiring the historical events and other elements penetrate into the game level, so that the students in the process of playing the game can stimulate students' development thinking, enhance memory; change the transmitting system of the boring knowledge teaching. For example, Shenyang Air Army developed a game "part flag always with me". In the racing game, a total of 53, each one needs to answer about the history of knowledge. In addition, the beginning and the end of the game is the held point of 1st CPC National Congress and 18th CPC National Congress. Level settings for this game can effectively stimulate students' interest in entertainment, at the same time, has adapted to the development of the data age, and effectively carry out the education of values. The value education of colleges and universities can also imitate the form, choose the right subject as the content of the game, and increase the interest.

Online game style education can effectively stimulate students' interest in thinking, helping students to improve their attention, to relax the mood, accept values education, easy to accept and memory. In addition, this way can change the traditional cramming method of teaching methods; stimulate the students' spirit, active classroom atmosphere and creating proper question situation for students to answer questions actively. The clearance of the game improves the students' sense of competition and challenge, through the form of team cooperation to enhance team awareness, thus improving the overall quality of College Students.

Stage Performance Education. This kind of education is to turn inspiring historical stories, moving stories into a stage show or a play on the campus net. Students being very enthusiastic about watching the show are necessary to watch the drama of the subtle character, but also enrich the students' spare time, which is a very popular form of values education. Stage drama can combine art and education to bring students the emotional resonance and bring real psychological experience. This can also help students form good learning habits. stage performance education in the past are used as a compulsory course in performance and other related professional, and less for the value view education, so in the use of this form, should pay attention to improve the teacher's professional quality, make full use of teacher resources, improve the level of the guidance of drama 
Scenario Simulation Thematic Education. As mentioned above, due to the diversified values of society, students' thinking activity, and so on, only relies on the knowledge and values of the sermon; the effect of education is not good. Therefore, the education workers in Colleges and universities should recognize the law of the physical and mental development of the students. This form of education is to simulate and reproduce the scene, so that college students in this situation, and constantly think ways to solve the problem, and further understand the teaching content, unconsciously accept the correct values of the influence. Through scenario simulation, students should have a deep sense of real social problems, stimulate students' thinking ability and potential, and constantly identify the correct ideas and concepts. In this way; it is able to combine the concept of internal and external behavior, so as to improve the pertinence of the education of values.

College educators in education of the scene simulation need to grasp the correct values and related knowledge, in order to help students understand correctly. First, the topics of the scenario simulation need to be carefully arranged the organized, including case selection, simulation conditions, the atmosphere of the building are required to be consider, as far as possible to ensure that the real and effective. Secondly, educators should have the ability to face the sudden situation, to ensure the smooth progress of the scene simulation and it is best to take into account the possible situation and response measures.

\section{Supports on the Concept of the Value Education Form Innovation}

Firstly, colleges and universities should break the boundaries of disciplines branch. many colleges and universities think that education is the knowledge, understand the whole meaning of teaching as the teaching of knowledge, and ignore the education of students' moral character and quality. Under the pressure of employment, the school is more emphasis on the training of specialized personnel training. This kind of education view is too narrow; the university should educate the people as an important task, to improve the comprehensive quality of college students, integrate the various disciplines of teacher resources and data resources, taking subject as the contents of the values education, training professional talents with interdisciplinary.

Secondly, renew teaching idea, set up the idea of light infusion and heavy experience. In the era of big data, the values of college and university gradually move towards the direction of pluralism and orientation, but there is still a heavy. So in the form of education reform and innovation should actively play the favorable conditions of interaction between teachers and students, cultural influence, at the same time, we should make use of the network teaching platform, using the modern teaching means to integrate data resources and educational advantages, change the traditional mode of knowledge theory of a single infusion, to achieve a multi form education model. In addition, in the process of diversified and three-dimensional values education practice activities, campus cultural activities can be used as an effective way to promote the value of education and theory of teaching penetration, integration.

Third, colleges and universities in the form innovation in the value of education should establish a people-oriented idea. In essence, the value education is educational activities to convince people, so the success of education is mainly to see whether it can start from the characteristics of students, whether it is suitable for the development of students. College students as individuals have a subjective initiative, is the subject of education, so only the values of education in line with the needs of the subject can be understood and supported. Therefore, the university should take the physical and psychological characteristics of college students, age characteristics, interests, ideas and other aspects of the differences into account, truly from the perspective of students, care for students' growth and development of the psychological state, to provide students with the appropriate values of education, so that students are willing to accept education, and self-education

\section{Summary}

In the era of big data, all kinds of data resources are being excavated, and the values education of the university should grasp the opportunity and challenge and actively innovate. How to integrate 
the data resources and rationally use of them is the export of the educational form of innovative values. The author discusses three kinds of effective values education form: network game, stage performance, scene simulation and the education idea that the university should set up. Hope that the major colleges and universities can continue to explore the values education form for college students and the concept of form innovation, to improve the effectiveness and practicality of the education of values, enhance the comprehensive quality of contemporary college students, and promote their comprehensive and healthy development, and hope that the author's research can provide reference for reference.

\section{References}

[1] Tu Zipei, big data [M]. Guangxi: Guangxi Normal University press, 2012:57.

[2] English] Victor Mayer Schoenberg, Kenneth, Ku Keye. The era of big data [M]. Sheng Yang Yan, Zhou Tao. Hangzhou: Zhejiang People's publishing house, 2013:13.

[3] Cao Jun, 2007Value clarification theory and values education in Chinese Universities Master Thesis of Harbin Institute of Technology,23-43

[4] Du Juan. 2009 .The present situation and development trend of the research on the value of Chinese and foreign countries. Journal of Jining college, 30 (6): 95-98

[5] Gong Linlin, 2008. The practical significance of the education of values. Legal system and society, (4): 230

[6] He Yongjun, Zhou Xiaoli, 2009A comparative study of values education of Chinese and foreign university students. Journal of Changsha Railway University: Social Science Edition, 2009, 10 (2): 266-267

[7] Huang Lijian, 2004.Problems analysis and Countermeasures of College Students' Values Education Master Thesis of Huazhong Normal University, 9-33

[8] Xu Sheng, Wang Jun, Qi Yu Bo.Run tothe real problem and the live thought [N].Liberation Army Daily, 20140811.

[9] Huang Xiuzhuo, Li Fengyu. 2009Research on the effectiveness of socialist core values education of college students. The development of economy and society, (6): 143-146. 